\title{
Available Technologies and Materials for Waste Cooking Oil Recycling
}

\author{
Alberto Mannu ${ }^{1, *(D)}$, Sebastiano Garroni ${ }^{2, *(\mathbb{D})}$, Jesus Ibanez Porras ${ }^{3}(\mathbb{D})$ and Andrea Mele ${ }^{1,4}$ (D) \\ 1 Department of Chemistry, Materials and Chemical Engineering “G. Natta”, Politecnico di Milano, \\ Piazza L. da Vinci 32, 20133 Milano, Italy; andrea.mele@polimi.it \\ 2 Department of Chemistry and Pharmacy, via Vienna 2, University of Sassari, 07100 Sassari, Italy \\ 3 International Research Centre in Critical Raw Materials (ICCRAM), University of Burgos, \\ Plaza Misael Bañuelos s/n, 09001 Burgos, Spain; jesusibanez@ubu.es \\ 4 CNR-ICRM Istituto di Chimica del Riconoscimento Molecolare, 'U.O.S. Milano Politecnico', \\ 20131 Milano, Italy \\ * Correspondence: alberto.mannu@polimi.it (A.M.); sgarroni@uniss.it (S.G.)
}

Received: 14 February 2020; Accepted: 12 March 2020; Published: 22 March 2020

\begin{abstract}
Recently, the interest in converting waste cooking oils (WCOs) to raw materials has grown exponentially. The driving force of such a trend is mainly represented by the increasing number of WCO applications, combined with the definition, in many countries, of new regulations on waste management. From an industrial perspective, the simple chemical composition of WCOs make them suitable as valuable chemical building blocks, in fuel, materials, and lubricant productions. The sustainability of such applications is sprightly related to proper recycling procedures. In this context, the development of new recycling processes, as well as the optimization of the existing ones, represents a priority for applied chemistry, chemical engineering, and material science. With the aim of providing useful updates to the scientific community involved in vegetable oil processing, the current available technologies for WCO recycling are herein reported, described, and discussed. In detail, two main types of WCO treatments will be considered: chemical transformations, to exploit the chemical functional groups present in the waste for the synthesis of added value products, and physical treatments as extraction, filtration, and distillation procedures. The first part, regarding chemical synthesis, will be connected mostly to the production of fuels. The second part, concerning physical treatments, will focus on bio-lubricant production. Moreover, during the description of filtering procedures, a special focus will be given to the development and applicability of new materials and technologies for WCO treatments.
\end{abstract}

Keywords: waste cooking oil; biolubricant; biodiesel; recycling; vegetable oil filtration; vegetable oil degumming

\section{Introduction}

Amongst the many issues currently faced by the scientific community, the interest toward the optimization of resources, while reducing the environmental impact of new and existing production processes, are of major interest. The amount of research focused on these transversal topics are growing, exponentially, in many research fields [1]. As a general approach, to develop such ambitious research, many scientists have explored routes for the employment of waste as raw material in new productions, as well as for the reconversion of existing processes. This is not an easy road, as industry requires to reach such targets in a very short time. The most demanding step in this scientific activity is represented by the passage from a technology readiness level (TRL) of 3 (analytical and experimental critical function and/or characteristic proof of concept) to 6 (system/subsystem model or prototype 
demonstration in a relevant environment) [2]. In fact, the transfer of knowledge is often hampered by the limits of the current available technologies. In this context, the development of improved technologies and materials for the transformation of waste-based raw materials into valuable products represents a primary target to unlock many transformations that exist only at design level or laboratory scale [3].

Within the restricted list of potential waste-based raw materials-which can lead, if properly processed, to a multiple typology of products - waste cooking oil (WCO) stands out [4].

WCO pertains to the family of used vegetable oils (UVOs), which are considered waste that is dangerous for the environment [5]. WCOs are the main representatives of such family, as most of the collected UVOs arise from kitchens and catering industries [6]. As frying food represents the main worldwide employed cooking method, WCOs are geographically diffused and produced everywhere in large amounts. The yearly overall production of used vegetable oils exceeds 190 million metric tons, with the European Union (EU) contributing about 1 million tons/year $[7,8]$.

A proper handling of WCOs is mandatory in many countries (and currently the subject of political discussion in others) [9-11]. The issues regarding the treatment of WCOs are mainly two: the disposal-collection strategy, and the reconversion of the waste [12]. Disposal and collection systems will not be discussed in the present review paper, as a good amount of information about this specific topic can be found elsewhere $[4,13]$.

Regarding the reconversion of WCOs, they can be used as main raw materials in many industrial processes, such as bio-lubricant [14] or fuel [15-17] production, or as additives for asphalts [18] and animal feed [19]. Other possible employments of WCOs are strictly related to their chemical compositions. WCOs are basically a mixture of triglycerides and fatty acids, contaminated by some derivatives during the frying process, as free fatty acids (FFA), heterocycles, Maillard reaction products, and metal traces originated from pads and food leaching $[20,21]$. The specific composition of WCOs can also be exploited as useful sources of chemicals for the production of bio-plasticizers, syngas, and sorbents for volatile organic compounds (VOCs) [22,23].

In the present review paper, some technological advancements related to the employment of WCOs as raw materials will be described and discussed. A special focus will be given to the period that ranges from 2015 to early 2020.

\section{Technologies and Materials for the Chemical Treatment of WCOs}

In this section, chemical treatments of WCOs that are amenable to practical application will be discussed.

WCOs are mixtures of long chain fatty acids (mainly linoleic, linolenic, and oleic), in form of tridi- and mono-glycerides, and a variable percentage of free fatty acids (FFA); they represent a platform of raw materials for many industries [24].

The chemical composition of WCOs is quite similar to one of the parent edible oils, and differs from the former in terms of decomposition and leaching products. During the frying process, a portion of triglycerides, of the ester moiety, break down. The degree of such degradation depends on the number of frying cycles, frying time, temperature, and the specific vegetable oil [25]. Moreover, during deep frying, many volatile compounds are generated as a consequence of a combination between high temperature and oxygen, which promotes oxidation processes, and other transformations (e.g., the Maillard process) [26,27]. In addition, food and tool exposure during frying promote leaching, enriching the oil composition with metal traces, spices, and other organic molecules [28]. Analysis of the volatile fraction of WCOs reveal a complex mixture of chemicals, which include aldehydes, alcohols, dienes, and heterocycles. In particular, samples of commercial sunflower oil were analyzed by Mannu et al. [29], prior to and after several cycles of frying. Many chemicals were detected in the samples subject to frying, such as hexanal, heptanal, limonene, furan, 2-pentyl-, nonanal, 1-octen-3-ol, furfural, cyclohexanol-dimethyl-2, benzaldehyde, 2-nonenal, 2-furan-methanol, 2-decenal, 2-undecenal, and 2,4-decadienal. 
The changes in the chemical composition of oil during the frying process can be related to food and tool contamination and decomposition. Nevertheless, the relative amount of impurities generated during the cooking process is not elevated. It is possible to estimate, qualitatively, the chemical composition of WCOs through Nuclear Magnetic Resonance (NMR) analysis. ${ }^{1} \mathrm{H}$ NMR spectra show a low amount of contaminants (less than $5 \%$ ), confirming that WCOs are very similar, in terms of overall chemical composition, to the parent edible oils [29].

If, from one side, the low degree of contamination and degradation is enough to declare WCOs unfit for food applications [30,31], from the other side, it allows to set-up a (not particularly difficult) recycling process [32].

Typically, the treatment of collected WCOs involve a first gross filtration aimed to remove solid materials dispersed in the oil. This is followed by the direct introduction of crude material as raw material in the production, without the need of specific decontamination/transformation steps. Then, depending to the specific application, the WCO-raw material can be subject to different kinds of transformations.

A very diffuse procedure consists of exploiting the chemical composition of WCOs to generate esters in basic media, and in the presence of alcohol (esterification). Common esters produced by this route are the fatty acid methyl esters (FAMEs), derived by reaction with methanol, and fatty acid ethyl esters (FAEEs), obtained through esterification with ethanol. The industrial destination of FAMEs and FAEEs are usually employed in biodiesel production [33]. In that case, FAEEs show some advantages with respect to FAME as enhanced fuel properties, in terms of stability towards oxidation and superior lubricant power [34]. Regarding fuel application, the assessment of the acidity of the raw material is crucial. In fact, if the free acidity (FA) results higher than $2.5 \%-3 \%$, the raw material is not suitable for biodiesel, and is subject to previous procedures in order to reduce the amount of FA. This parameter represents one of the main economic indicators for collectors, because it determines the selling price when WCOs are delivered to biodiesel facilities [35]. For companies involved in collecting and delivering large amounts of WCO, the cost for reducing the amount of FA can be elevated. However, on a small scale, collectors can blend WCOs with different acidity until it reaches the appropriate level of FA required by the producers. The possibility to easily bypassing the issue on a small scale allows the collectors to focus more on the optimization of the recovery step, enhancing their competitiveness. In such conditions, the biggest cost is represented by the acquisition of a proper warehouse for WCO storage, which need to be blended. This last aspect can double the rental price and increase the energy consumption to maintain the oil in adequate conditions.

The acidity index of WCOs is also chemically relevant, as it influences the rate of the collateral hydrolysis of the triacylglycerols, which occur during the basic esterification (saponification).

Saponification gives rise to a relevant issue for industries: the formation of emulsions-they are difficult to reduce on a big scale (in biodiesel plants, for example) [36]. The formation of soap is also promoted by the presence of water in WCOs. For this reason, WCOs are often subject to water removing procedures - usually based on decantation - prior to being sold to biodiesel producers.

On the other side, WCOs that are destined to be processed in soap facilities do not have such $\mathrm{pH}$ limitation, as the raw materials are processed by a harsh basic treatment. This subject was recently described in a review article by Felix and coworkers [37].

A relevant amount of research has focused on developing routes to avoid collateral saponification during methyl ester synthesis from WCOs. Fereidooni et al. recently reported an electrolytic process for the esterification of WCOs in the presence of $\mathrm{MeOH}$ and $\mathrm{KOH}$ to obtain FAMEs. In such conditions, the collateral saponification does not occur even in the presence of consistent amounts of water [38].

Moreover, esterification of WCOs do not generate negligible amounts of glycerol, which can promote a collateral transesterification reaction. In order to avoid undesired transesterification, and considering the commercial value of glycerol, this is usually recovered and exploited in parallel processes [39]. 
As a matter of fact, acidic esterification of WCOs is also possible, and it can be employed for the batch of raw oil, showing elevated values of acidity; thus, not being suitable for biodiesel [40]. Acid-catalyzed esterification of WCOs to FAME was achieved by Quintain and coworkers [41] by employing a graphene oxide-based catalyst under microwave irradiation.

A general overview of the main reactivity of WCOs in different conditions is reported in Scheme 1.

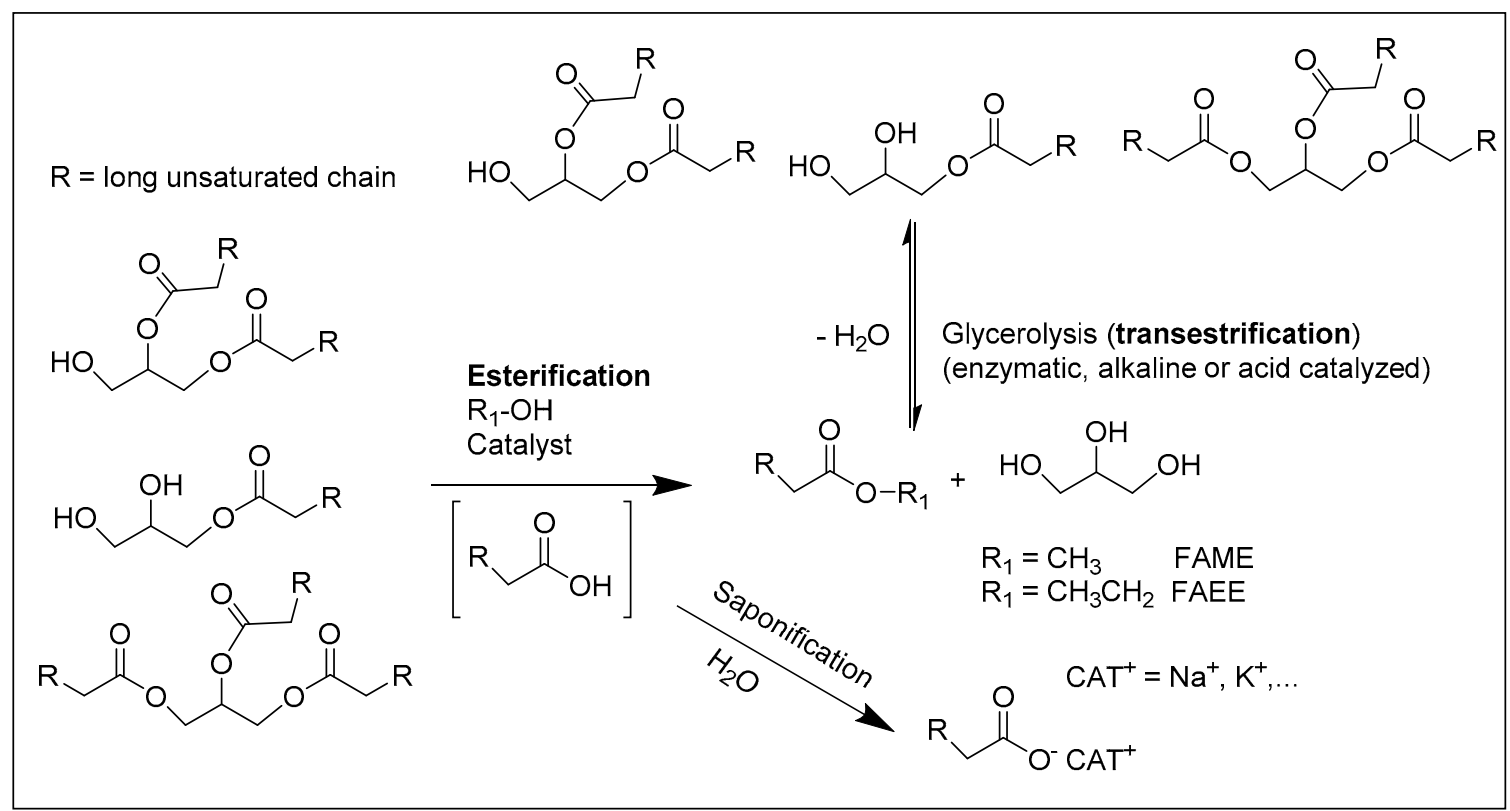

Scheme 1. Esterification of waste cooking oils (WCOs) and related processes.

An alternative alcohol to methanol and ethanol for esterification of WCOs is the glycerol. In that case, the reaction is known as glycerolysis, and in the case of WCOs, formally regenerates, in part, the original composition of the oil (Scheme 1) [42].

The glycerolysis can be exploited for increasing the added value of the starting materials (WCOs) by transforming the free fatty acids (FFA) contained in the waste into added-value chemicals. Monoand di-glycerides are used as surfactants [43] or as emulsifiers in the food, cosmetic, and pharmaceutical industry [44], while tri-glycerides are employed as additives in bio-diesel production $[45,46]$.

Regarding the effectiveness of glycerolysis, the main issue is represented by the low miscibility of glycerol and waste oil. The problem has been faced for decades; optimized protocols, which usually employ high temperature conditions, have been proposed. Recently, advances toward milder WCO glycerolysis have been reported by Supradan and coworkers [47], who proposed the use of hexane as co-solvent for undertaking mass transfer problems generated by the low solubility of glycerol. Alternatively, Mazubert et al. [48] proposed to perform the glycerolysis of FFA in a reactor system.

Catalytic production of bio-diesel has also faced updates in previous years. Abdillah et al. [49] described the combination of activated carbon obtained from palm oil biomass and potassium phosphate tri-basics $\left(\mathrm{K}_{3} \mathrm{PO}_{4}\right)$ as a heterogeneous catalyst for fatty acid methyl esters (FAME) production from WCOs.

Moving to the homogeneous phase, Borovinskaya and coworkers [50] reported the catalyzed trans-esterification of WCOs to obtain FAEEs, performed in a micro-/milli-reactor.

The synthesis of WCO-derived esters can also be exploited in the bio-lubricant industry. What is interesting is the case of the trimethylolpropane fatty acid trimethyl ester, which can be used as a lubricant base stock with superior lubricant power, stability, and biodegradability, with respect to other pentaerythritol fatty esters (TFATEs) [51]. These lubricants can be obtained by transesterification between FAME and trimethylolpropane (TMP) [52] or by esterification of FFAs with TMP. A recent contribution to this specific topic has been offered by Sun and coworkers [53], who proposed the 
production of TFATEs through transesterification of WCO-derived FAME, with TMP mediated by a catalyst based on a mixture between hydrotalcite and potassium carbonate $\left(\mathrm{K}_{2} \mathrm{CO}_{3}\right)$. Recycling of the catalyst, combined with waste-based raw material, makes this process economic and low-impacting. An analogue process, which involves a different catalyst (Mg-Al/hydrotalcite) was recently described by Costarosa et al. [54], and then optimized by the multivariate statistic and response surface analysis (RSA). As a result of such studies, for biodiesel applications, basic catalyzed esterification seems to be the preferred methodology, mainly due to the development of specific process conditions that avoid the formation of emulsions. Similar optimization tools were employed by Mannu et al. [55], who reported optimized conditions for the production of bio-lubricants from water treatment of WCOs as result of RSA. The availability of effective tools to optimize the bio-lubricant production by water treatment of WCOs make this last process competitive, with respect to the filtration procedures, which have been historically employed as a main purification step in vegetable oil refining.

\section{Technologies and Materials for the Physical Treatment of WCOs}

Physical treatment of WCOs is basically aimed at removing undesired products from crude WCOs, and to obtain a regenerated oil enriched in fatty acids. It is possible to consider three physical routes for achieving WCO regeneration:

(1) Separation based on solubility.

(2) Separation through filtration with specific materials.

(3) Separation based on the boiling point (distillation).

\subsection{Separation Based on Solubility}

Regarding the separation process based on solubility, water is the solvent of choice. In fact, as the oil is immiscible with water, many chemicals contained in WCOs can easily be removed from WCOs by simply washing the crude material. This procedure can also be extended to an industrial environment by employing a metallic tank equipped with a mechanical stirrer. This (very easy) configuration has been known, for many years as "degumming" (for its purification of vegetable oils). Its aim is to remove phospholipids and waxes [56]. Some local industries employ this procedure for the production of bio-lubricants from WCOs, with any further optimization. Nevertheless, recent research has revealed non-negligible room for improvement. In fact, by tuning the $\mathrm{pH}$ of the water, as well as working at specific temperatures and with determined stirring times, it is possible to increase the density, the flash point, and the color of the resulting bio-lubricant [57]. Vlahopoulou et al. [57] reported that by changing the degumming conditions, only small changes could be observed in the density values, while the flash point was much more sensitive to the process parameters. In particular, WCOs subject to different water treatments show a flash point number that ranges from $270{ }^{\circ} \mathrm{C}\left(\mathrm{pH}=4,20^{\circ} \mathrm{C}, 5 \mathrm{~h}\right.$ of stirring, and oil/water wt $\%$ ratio $=30)$, to $290^{\circ} \mathrm{C}\left(\mathrm{pH}=6,60^{\circ} \mathrm{C}, 5 \mathrm{~h}\right.$ of stirring, and oil/water wt $\%$ ratio $=30$ ). In Table 1 , the variation of the flash point of WCOs after degumming at different conditions is reported. The possibility to increase the flash point value by tuning the previous described parameters is of high industrial interest as it can directly influence the quality of the refined bio-lubricant.

As the variation of the physical parameters is the result of a change in the chemical composition, Mannu and coworkers went through the matter and studied the variation of the volatile profile of WCO samples subjected to water degumming (Table 1) [29].

Looking at the data reported in Table 1, it is possible to confirm the formation of several volatile compounds during the life-cycle of the vegetable oil and their partial removal as a result of the water treatment. As expected, working on $\mathrm{pH}$ and temperature range, it is possible to selectively remove specific functional groups, as heptanal and limonene, which are removed only in acidic conditions. This methodology presents some drawbacks, as the saponification observed at $\mathrm{pH}=9$ (which generates undesired emulsions) or the possibility of corrosion issues when the process treatment is performed at $\mathrm{pH}=3[30]$. 
Table 1. Variation of the volatile profile in samples of edible oil M1, fried oil WCO1, and degummed samples [29].

\begin{tabular}{|c|c|c|c|c|c|c|c|c|}
\hline Entry & $\begin{array}{l}\text { Retention } \\
\text { Time }\end{array}$ & M1 & WCO1 $^{1}$ & $\begin{array}{c}\mathrm{pH}=3 \\
\text { and } \mathrm{T}= \\
25^{\circ} \mathrm{C}\end{array}$ & $\begin{array}{c}\mathrm{pH}=9 \\
\text { and } \mathrm{T}= \\
25^{\circ} \mathrm{C}\end{array}$ & $\begin{array}{c}\mathrm{pH}=3 \\
\text { and } \mathrm{T}= \\
80^{\circ} \mathrm{C}\end{array}$ & $\begin{array}{c}\mathrm{pH}=9 \\
\text { and } \mathrm{T}= \\
80^{\circ} \mathrm{C}\end{array}$ & Analyte \\
\hline 1 & 15.489 & n.d. & 2.7287 & 1.9981 & 1.7933 & 0.8577 & 1.8302 & Hexanal \\
\hline 2 & 19.009 & n.d. & 0.7503 & 0.2685 & 0.3263 & - & 0.6493 & Heptanal \\
\hline 3 & 19.573 & n.d. & 0.7684 & - & 0.4901 & - & 0.4494 & Limonene \\
\hline 4 & 20.354 & n.d. & 1.8623 & 1.0677 & 1.2202 & - & 0.4494 & Furan, 2-pentyl- \\
\hline 5 & 25.183 & n.d. & 4.0382 & 3.8689 & 4.0172 & 2.8489 & 2.4767 & Nonanal \\
\hline 6 & 26.086 & n.d. & 0.8284 & 0.6770 & 0.8705 & 0.4485 & 0.7353 & 1-octen-3-ol \\
\hline 7 & 27.052 & n.d. & 0.6783 & - & 0.5719 & 0.0791 & 0.1544 & Furfural \\
\hline 8 & 29.158 & n.d. & 0.5625 & 0.4577 & 0.4587 & 0.1700 & 0.5569 & Cyclohexanol $^{2}$ \\
\hline 9 & 29.475 & n.d. & 0.4908 & 0.4230 & 0.4550 & 0.2407 & 0.2646 & Benzaldehyde \\
\hline 10 & 29.692 & n.d. & 0.6348 & 0.6042 & 0.5006 & 0.4925 & 0.7101 & 2-Nonenal \\
\hline 11 & 32.182 & n.d. & - & - & - & - & - & 2-Furan-methanol \\
\hline 12 & 32.423 & n.d. & 1.4988 & 1.4236 & 1.4708 & 1.3255 & 1.5066 & 2-Decenal \\
\hline 13 & 34.587 & n.d. & 1.0504 & 1.0649 & 1.0810 & 1.0060 & 0.6942 & 2-Undecenal \\
\hline 14 & 34.79 & n.d. & 1.2092 & 1.1551 & 1.1331 & 1.0718 & 1.0759 & 2,4-Decadienal ${ }^{2}$ \\
\hline
\end{tabular}

\subsection{Separation Through Filtration with Specific Materials}

Particle sequestration and separation represents the essence of the recycle process and its efficiency depends on the particulate that can be retained, the volume of the filtrate that can flow through the filter, and physicochemical properties of the filtered oil upon the process. Physical and chemical regeneration of waste frying oils can be typically divided into three main technological approaches: membrane treatment, conventional, and activate filtration. Both the aforementioned approaches exploit different solid materials, which characterize performance, cost, and sustainability of the whole recycling process.

In the last two decades, membrane technology application in vegetable oil processing has received increasing attention due to different advantages, including low energy consumption (approximately $50 \%$ with respect to the conventional filtration), and retention of nutrient components [59]. Membranes can be defined as a semipermeable barrier, allowing the passage of components (in this case the vegetable oil) and the retention of others (i.e., the undesired products produced after frying at a high temperature). Membrane filtration is a process driven by the pressure applied and the size of by-products. Two main classes of materials are used for producing commercial membranes: (i) polymers consisting of cellulose acetate, polyamide, polysulfone, and polyvinylidene difluoride (PVDF); and (ii) ceramic and metals materials, including alumina and stainless steel. Moreover, ultra(UF) and nano-filtration membranes, characterized by their specific pore dimensions $(<1 \mu \mathrm{m})$, have been largely explored to remove, for example, triglycerides and phospholipids during the degumming step [60]. As an example, a membrane based on PVDF can sequestrate over $98 \%$ of phospholipid, with excellent resistance to fouling during the degumming process, and high permeate fluxes, making this membrane very promising for industrial application [61,62]. Furthermore, in addition to phospholipids, these specific membranes can remove up to $80 \%$ of color from WCOs [63]. Typically, the filtration process, which involves membrane apparatus at lab scale, is carried out under pressure of $2-5$ bars, flow velocity of $0.3-0.4 \mathrm{~L} / \mathrm{m}^{3}$, and in a temperature range of $40-60{ }^{\circ} \mathrm{C}$ [62]. Ultrafiltration of membrane prepared from polyethersulfone (PES), removed up to $89 \%$ of phospholipid leading to a color reduction, expressed in yellow units of 25\% [64]. Recently, Onal-Ulusoy and coworkers improved, significantly, PES-based membrane sequestration activity for waste frying oil recycling, modifying their surfaces by radio frequency (RF) plasma treatment [65]. During membrane filtration, triglyceride components permeated preferentially compared to the polar compounds including oxidation and hydrolysis products and polymers. The experimental results showed that PES membranes, surface modified with HMDSO at $75 \mathrm{~W}$ for $5 \mathrm{~min}$, retain selectively free fatty acids (FFAs) of waste frying oil, up to $35.3 \%-40 \%$, 
and reduced the oil viscosity $9.4 \%$ to $12.8 \%$. Finally, the use of membrane technology appears as a promising alternative to the conventional method of waste oil processing, due to its suitability to be applied at different stages of the whole recycle process (degumming, refining, etc.) and its low energy consumption. However, in order to drastically improve their performance, and to overcome some barriers represented by the optimization of the permeate flow rates, a deeper investigation on the materials is necessary.

Conventional filters, used in the filtration apparatus, include a pad of cellulose fibers and metal screens. Cellulose filters, for example, are very cheap if compared to other materials. Recently, Malagon-Rometo et al. [66] developed and standardized a process to treat Colombian waste cooking oils, which removes $79 \%$ of the solid particles, employing paper filter (cellulose). However, cellulose pads absorb an important amount of the filtered oil and they can only retain particles with dimensions larger than $1 \mu \mathrm{m}$. Furthermore, they present poor mechanical properties and are often damaged after removing particulates adsorbed after filtration, reducing their use for multiple filtration cycles (up to $600 \mathrm{~kg}$ of oil). Stainless steel filter screens, on the other hand, can be reused indefinitely, but are more expensive then cellulose pads, and their efficiency separation is limited to particles large than $80 \mu \mathrm{m}$. In order to increase filtration efficiency, typically, a powdered filter aid can be used in combination with a conventional filter. Such filter aids are deposited in the main filter surface, increasing the filtration surface area and then enhancing the retention of smaller particles (around $1 \mu \mathrm{m}$ ). At the same time, filter aids also include adsorbents or neutralizing agents to provide active filtration, as a consequence of chemical interaction and/or electrostatic bonding with free fatty acid contaminants. Examples of filter aids include inorganic compounds, such as diatomaceous earth, clays, silicates, and activated carbons. In the past, synthetic calcium and magnesium silicate has been extensively used to reduce FFA and color, respectively [67]. During the last 20 years, new filter aid products have been synthesized, including blends of silicates with magnesium and aluminum oxides, which have been included into the process for treating used cooking oil in frying operations $[68,69]$. With the same purpose, filters composed by synthetic fibers of polyester, polypropylene, and nylon, have been developed and tested in a very efficient process, able to remove $93 \%-98 \%$ of fatty acids from cooking oil used [70,71].

Currently, it is possible to find on the market some small-scale machines for WCO regeneration. The exploitability of such technological solutions is strongly influenced by local legislation, as in some countries, the recycling of WCO for food purposes is strictly regulated [72]. For example, some companies sell recycling apparatuses to extend the life of frying oil, claiming to reach up to $50 \%$ of additional cooking time [73].

Despite the high performing capacity to remove particulates displayed by conventional, powdered, and fiber filters, the retention of smaller, undesired particles $(<0.5 \mu \mathrm{m})$ remains a not-yet solved problem. These materials are, in fact, characterized by medium-low surface areas $\left(<500 \mathrm{~m}^{2} / \mathrm{g}\right)$ and macroporosity $(\mathrm{d}>0.1 \mu \mathrm{m})$. For this reason, increasing attention has been addressed, in previous years, to mesoporous and microporous materials with pore size dimensions of $2-50 \mathrm{~nm}$, and very high specific surface areas $\left(>500 \mathrm{~m}^{2} / \mathrm{g}\right)$ to act as sorbent systems for small particles formed in the cooking oil during the frying process. Recently, for example, it was found that aluminum-, zinc- and titanium-containing metal-organic frameworks (Al-, Zn-, and Ti-MoF) improve significantly, with respect to traditional filters, taste, and odor properties of unrefined vegetable oils, due to the binding of free fatty acids and peroxide compounds [74]. Unfortunately, the high cost synthesis and regeneration treatment are main barriers for rapid commercialization of this class of materials, for this specific purpose. Therefore, it is no surprise that the attention from part of the scientific community, even if only recently, has moved to test natural porous materials, such as bentonites [75]. For example, montmorillonite (the dominant component of bentonite), tested for WCO purification, seems to retain specific chemical groups, such as carboxylic acids or double bonds, significantly improving the color quality of the filtered oil [76].

A transfer of knowledge attempt, based on a combination of water treatment and filtration on porous materials, has been made by Mannu and coworkers, by designing a recycling mini-plant aimed to produce bio-lubricants from WCOs (Figure 1) [29]. 




Figure 1. Process for WCO recycling, Mannu et al. [29].

The proposed process can be schematized as follows: WCO is subject to water treatment while the waste-water is discharged. The degummed waste oil is then pushed through a pressure pipeline until the filtering module, where it is treated with a porous material. Pressure filtration (4 bar) was described by the authors for pushing the intermediate oil through a fiberglass container containing the filtering material. A "deep bed" filtration was proposed, where the oil crosses the length of the filter. The combination between degumming and filtration affords a refined, recycled vegetable oil.

Despite the many progresses achieved in the field of such filters, further efforts are necessary to improve the performance and cost sustainability. In particular, fervent research is still required to decrease the amount of oil absorbed on the cellulose filters, to reduce the cost of synthesis and regeneration of synthetic materials and, last but not least, to understand the microscopic mechanisms behind the sequestration process, fundamental for improving the adsorbing properties of these materials up to their industrial scale-up and commercialization.

\subsection{Separation Based on the Boiling Point (Distillation)}

Distillation of WCOs also deserves to be described. In fact, the simplicity of such treatment, which is mainly aimed at removing volatile compounds and water from crude WCOs, allowed the commercial production of machines for small-scale WCO recycling. Nowadays, it is possible to buy a waste oil recycling machine for less than 15,000 USD [77].

These machines, for WCO recycling, are basically mini distillation plants. The general process applied to the raw material can be resumed as follows: the crude oil is subject to a gross filtration, aimed to remove solid contaminants, and then heated under vacuum. Through reduced pressure distillation, the crude oil is purified from the volatile fraction, resulting in a regenerate oleic product. After the deodorization procedure, the recycled vegetable oil can be sold as low quality lubricant, or as raw material for other industries, as fuel, high quality bio-lubricant, or soap productions.

This technology presents some evident advantages, as the reduced dimensions (from $1 \mathrm{~m} \times 1.5 \mathrm{~m}$ $\times 1.2 \mathrm{~m}$ ), fast processing time (flow rate from $10 \mathrm{~L} / \mathrm{min}$.), and low working temperature (less than $100^{\circ} \mathrm{C}$ ) [78]. On the other hand, it requires continuous electricity consumption, and it works under reduced pressure, which could reveal important issues in a working environment.

The energetic request is not very high (from $38 \mathrm{~kW}$ ) and the process can be considered quite economic. It is possible to estimate a consumption of $1.583 \mathrm{kWh}$ to produce 25 tons of purified oil, which corresponds to an overall energetic cost of approximately $7 €$ (euros) per ton of purified oil, based on the average energy prices in Europe for non-household consumers $(0.11 € / \mathrm{kWh})$ [79].

Regarding the quality of the recycled oil, it depends on the specific configuration of the machine, as well as the quality of the raw WCO. As a matter of fact, these machines can be employed to produce low quality lubricants from waste, which can be employed or sold as such, or can be further processed for refinement. This technology can be used directly from the end-user, also, to regenerate exhausted lubricants employed in close circuits. In particular, the bio-lubricants market share is fast growing, and 
during previous years, showed a Compound Annual Growth Rate (CAGR) of 5\%, with US and Europe playing the role of major consumers [80].

Recycled cooking oils obtained by distillation, filtering, or by combination of the formers, can be sold as chainsaw lubricants, or as solvents. In the first case, depending to the required quality, some further refining could be necessary, especially for increasing the oxidation stability and pour point, e.g., by esterification and/or by addition of antioxidants [81]. In the second case, recycled vegetable oil can be transformed in many derivatives, such as alkyds, poly(esteramide)s, poly(etheramide)s, polyurethanes, epoxies, and glycerol, which, blended with natural pigments, can find applications as biodegradable coatings and paints [82].

\section{Conclusions}

Waste cooking oils (WCOs) represent a valuable source of raw materials with a wide range of applications, from energy to lubricants or soaps. Moreover, due to their waste-nature and to a huge and diffused availability, WCOs fit well in the circular economy model, resulting in interest for their integration into existing processes, as well as for the development of new sustainable productions. Old techniques and technologies regarding the transformation of vegetable oils are, nowadays, object to specific updates in order to be adapted to the current characteristics requested by modern companies. This modernization in WCO treatment includes, not only a research activity on more convenient chemical syntheses, but also the development of new materials, and the definition of new combined treatments, which involve different techniques integrated. Looking at the recent bibliography related to the recycling of WCOs, a first chemical transformation of the crude material, mainly through esterification, represents a transversal topic; many authors deal with biodiesel as well as bio-lubricant applications. Nevertheless, technological advancements, both in terms of processes and materials, aimed to recycle WCOs in a more efficient and sustainable way, are gaining attention. In this regard, mini plants based on fast physical treatment of waste oils (mostly by distillation), are nowadays available on the market. Looking at the future, the integration between academic and industrial research activities will be fundamental in order to develop recycling treatments that are truly able to substitute existing productions, which involve non-waste raw materials.

Author Contributions: Conceptualization, A.M. (Alberto Mannu) and S.G.; methodology, A.M. (Alberto Mannu) and S.G.; investigation, J.I.P.; data curation, A.M. (Alberto Mannu) and S.G.; writing-original draft preparation, A.M. (Alberto Mannu) and S.G.; writing—review and editing, A.M. (Andrea Mele); visualization, S.G.; supervision, A.M. (Alberto Mannu); project administration, A.M. (Alberto Mannu) and S.G. All authors have read and agreed to the published version of the manuscript.

Funding: This research received no external funding.

Acknowledgments: The authors thank Sonia Martel Martin for the kind help in managing the collaboration with UBU and all of the people involved from the MSCA RISE 2019 project proposal WORLD (873005).

Conflicts of Interest: The authors declare no conflict of interest.

\section{References}

1. Marion, P.; Bernela, B.; Piccirilli, A.; Estrine, B.; Patouillard, N.; Guilbot, J.; Jérôme, F. Sustainable chemistry: How to produce better and more from less? Green Chem. 2017, 19, 4973-4989. [CrossRef]

2. Rybicka, J.; Tiwari, A.; Leeke, G.A. Technology readiness level assessment of composites recycling technologies. J. Clean. Prod. 2016, 112, 1001-1012. [CrossRef]

3. De Almeida, S.T.; Borsato, M. Assessing the efficiency of End of Life technology in waste treatment-A bibliometric literature review. Resour. Conserv. Recycl. 2019, 140, 189-208. [CrossRef]

4. Borrello, M.; Caracciolo, F.; Lombardi, A.; Pascucci, S.; Cembalo, L. Consumers' Perspective on Circular Economy Strategy for Reducing Food Waste. Sustainability 2017, 9, 141. [CrossRef]

5. European Waste Catalogue, Code Number 2001 25. Available online: https://eur-lex.europa.eu/legal-content/ EN/TXT/PDF/?uri=CELEX:02000D0532-20150601\&from=EN (accessed on 10 February 2020).

6. Choe, E.; Min, D.B. Chemistry of Deep-Fat Frying Oils. J. Food Sci. 2007, 72, R77-R86. [CrossRef] [PubMed] 
7. Statista-The portal for statistics. Consumption of Vegetable Oils Worldwide From 2013/14 To 2017/2018, by Oil Type (in Million Metric Tons). Available online: https://www.statista.com/statistics/263937/vegetable-oilsglobalconsumption (accessed on 10 February 2020).

8. Lin, C.S.K.; Pfaltzgraff, L.A.; Herrero-Davila, L.; Mubofu, E.B.; Abderrahim, S.; Clark, J.H.; Koutinas, A.A.; Kopsahelis, N.; Stamatelatou, K.; Dickson, F.; et al. Food waste as a valuable resource for the production of chemicals, materials and fuels. Current situation and global perspective. Energy Environ. Sci. 2013, 6, 426-464. [CrossRef]

9. Gurbuz, I.B.; Ozkan, G. Consumers' knowledge, attitude and behavioural patterns towards the liquid wastes (cooking oil) in Istanbul, Turkey. Environ. Sci. Pollut. Res. 2019, 26, 16529-16536. [CrossRef]

10. Liu, T.; Liu, Y.; Luo, E.; Wu, Y.; Li, Y.; Wu, S. Who is the most effective stakeholder to incent in the waste cooking oil supply chain? A case study of Beijing, China. Energy Ecol. Environ. 2019, 4, 116-124. [CrossRef]

11. Tsai, W.-T. Mandatory Recycling of Waste Cooking Oil from Residential and Commercial Sectors in Taiwan. Resources 2019, 8, 38. [CrossRef]

12. Ribau-Teixeira, M.; Nogueira, R.; Nunes, L.M. Quantitative assessment of the valorisation of used cooking oils in 23 countries. Waste Manag. 2018, 78, 611-620. [CrossRef]

13. Rodrigues Pereira Ramos, T.; Gomes, M.I.; Barbosa-Póvoa, A.P. Planning waste cooking oil collection systems. Waste Manag. 2013, 33, 1691-1703. [CrossRef] [PubMed]

14. Karmakar, G.; Ghosh, P.; Sharma, B. Chemically Modifying Vegetable Oils to Prepare Green Lubricants. Lubricants 2017, 5, 44. [CrossRef]

15. Hazrat, M.A.; Rasul, M.G.; Khan MM, K.; Ashwath, N.; Rufford, T.E. Emission characteristics of waste tallow and waste cooking oil based ternary biodiesel fuels. Energy Procedia 2019, 160, 842-847. [CrossRef]

16. Ray, S.K.; Prakash, O. Biodiesel Extracted from Waste Vegetable Oil as an Alternative Fuel for Diesel Engine: Performance Evaluation of Kirlosker $5 \mathrm{~kW}$ Engine. In Renewable Energy and its Innovative Technologies; Springer: Berlin/Heidelberg, Germany, 2019.

17. Chrysikou, L.P.; Dagonikou, V.; Dimitriadis, A.; Bezergianni, S. Waste cooking oils exploitation targeting EU 2020 diesel fuel production: Environmental and economic benefits. J. Clean. Prod. 2019, 219, 566-575. [CrossRef]

18. Rayhan, B.A.; Kamal, H. Waste cooking oil as an asphalt rejuvenator: A state-of-the-art review. Constr. Build. Mater. 2020, 230, 116985.

19. Magrinyà, N.; Tres, A.; Codony, R.; Guardiola, F.; Nuchi, C.D.; Bou, R. Use of recovered frying oils in chicken and rabbit feeds: Effect on the fatty acid and tocol composition and on the oxidation levels of meat, liver and plasma. Animal 2012, 7, 505-517.

20. Chung, T.Y.; Eiserich, J.P.; Shibamoto, T. Volatile compounds identified in headspace samples of peanut oil heated under temperatures ranging from 50 to 200.degree.C. J. Agric. Food Chem. 1993, 41, 1467-1470. [CrossRef]

21. Wu, C.M.; Chen, S.Y. Volatile compounds in oils after deep frying or stir frying and subsequent storage. J. Am. Oil Chem. Soc. 1992, 69, 858-865. [CrossRef]

22. Mannu, A.; Ferro, M.; Di Pietro, M.E.; Mele, A. Innovative Applications of Waste Cooking Oil as Raw Material. Sci. Prog. 2019, 102, 153-160. [CrossRef]

23. Panadare, D.C.; Rathod, V.K. Applications of Waste Cooking Oil Other Than Biodiesel: A Review. Iran. J. Chem. Eng. 2015, 12, 55-76.

24. Singhabhandhu, A.; Tezuka, T. The waste-to-energy framework for integrated multi-waste utilization: Waste cooking oil, waste lubricating oil, and waste plastics. Energy 2010, 35, 2544-2551. [CrossRef]

25. Awogbemi, O.; Onuh, E.I.; Inambao, F.L. Comparative study of properties and fatty acid composition of some neat vegetable oils and waste cooking oils. Int. J. Low Carbon Technol. 2019, 14, 417-425. [CrossRef]

26. Ziaiifar, A.M.; Achir, N.; Courtois, F.; Trezzani, I.; Trystram, G. Review of mechanisms, conditions, and factors involved in the oil uptake phenomenon during the deep-fat frying process. Int. J. Food Sci. Technol. 2008, 43, 1410-1423. [CrossRef]

27. Saguy, I.; Dana, D. Integrated approach to deep fat frying: Engineering, nutrition, health and consumer aspects. J. Food Eng. 2003, 56, 143-152. [CrossRef]

28. Pokorny, J. Flavor chemistry of deep fat frying in oil. In Flavor Chemistry of Lipid Foods; Min, D.B., Smouse, T.H., Zhang, S.S., Eds.; American Oil Chemists Society: Champaign, IL, USA, 1989. 
29. Mannu, A.; Ferro, M.; Colombo Dugoni, G.; Panzeri, W.; Petretto, G.L.; Urgeghe, P.; Mele, A. Recycling of Waste Cooking Oils: Variation of the Chemical Composition during Water Treatment. Preprints 2019, 160, 842-847. [CrossRef]

30. Li, J.; Cai, W.; Sun, D.; Liu, Y. A Quick Method for Determining Total Polar Compounds of Frying Oils Using Electric Conductivity. Food Anal. Methods 2016, 9, 1444-1450. [CrossRef]

31. Firestone, D. Deep Frying: Chemistry, Nutrition, and Practical Applications, 2nd ed.; Erickson, M.D., Ed.; Elsevier: Amsterdam, The Netherlands, 2007; pp. 373-385. [CrossRef]

32. Mannu, A.; Ferro, M.; Colombo Dugoni, G.; Panzeri, W.; Petretto, G.L.; Urgeghe, P.; Mele, A. Improving the recycling technology of waste cooking oils: Chemical fingerprint as tool for non-biodiesel application. Waste Manag. 2019, 96, 1-8. [CrossRef]

33. Fu, J.; Turn, S.Q.; Takushi, B.M.; Kawamata, C.L. Storage and oxidation stabilities of biodiesel derived from waste cooking oil. Fuel 2016, 167, 89-97. [CrossRef]

34. Reyero, I.; Arzamendi, G.; Zabala, S.; Gandía, L.M. Kinetics of the NaOH-catalyzed transesterification of sunflower oil with ethanol to produce biodiesel. Fuel Process. Technol. 2015, 129, 147-155. [CrossRef]

35. García Martín, J.F.; del Carmen López Barrera, M.; Torres García, M.; Zhang, Q.-A.; Álvarez Mateos, P. Determination of the Acidity of Waste Cooking Oils by Near Infrared Spectroscopy. Processes 2019, 7, 304. [CrossRef]

36. Banerjee, A.; Chakraborty, R. Parametric sensitivity in transesterification of waste cooking oil for biodiesel production-A Review. Resour. Conserv. Recycl. 2009, 53, 490-497. [CrossRef]

37. Félix, S.; Araújo, J.; Pires, A.M.; Sousa, A.C. Soap production: A green prospective. Waste Manag. 2017, 66, 190-195. [CrossRef]

38. Fereidooni, L.; Tahvildari, K.; Mehrpooya, M. Trans-esterification of waste cooking oil with methanol by electrolysis process using KOH. Renew. Energy 2018, 116, 183-193. [CrossRef]

39. Cai, Z.-Z.; Wang, Y.; Teng, Y.-L.; Chong, K.-M.; Wang, J.-W.; Zhang, J.-W.; Yang, D.-P. A two-step biodiesel production process from waste cooking oil via recycling crude glycerol esterification catalyzed by alkali catalyst. Fuel Process. Technol. 2015, 137, 186-193. [CrossRef]

40. Álvarez-Mateos, P.; García-Martín, J.F.; Guerrero-Vacas, F.J.; Naranjo-Calderón, C.; Barrios-Sánchez, C.C.; Pérez-Camino, M.C. Valorization of a high-acidity residual oil generated in the waste cooking oils recycling industries. Grasas Aceites 2019, 70, e335. [CrossRef]

41. Quitain, A.T.; Sumigawa, Y.; Mission, E.G.; Sasaki, M.; Assabumrungrat, S.; Kida, T. Graphene Oxide and Microwave Synergism for Efficient Esterification of Fatty Acids. Energy Fuels 2018, 32, 3599-3607. [CrossRef]

42. Costa, E.; Cruz, M.; Alvim-Ferraz, C.; Almeida, M.F.; Dias, J.M. WASTES-Solutions, Treatments and Opportunities II. In Proceedings of the 4th International Conference Wastes: Solutions, Treatments and Opportunities, WASTES 2017, Porto, Portugal, 25 September 2017.

43. Nurdin, S.; Yunus, R.M.; Nour, A.H.; Gimbun, J.; Aisyah, N.; Azman, N.; Sivaguru, M.V. Restoration of Waste Cooking Oil (WCO) Using Alkaline Hydrolysis Technique (ALHYT) for Future Biodetergent. ARPN J. Eng. Appl. Sci. 2016, 11, 6405-6410.

44. Liu, W.-Q.; Yang, S.-Z.; Gang, H.-Z.; Mu, B.-Z.; Liu, J.-F. Efficient emulsifying properties of monoglycerides synthesized via simple and green route. J. Dispers. Sci. Technol. 2019, 1-9. [CrossRef]

45. Mićić, R.; Tomić, M.; Martinović, F.; Kiss, F.; Simikić, M.; Aleksic, A. Reduction of free fatty acids in waste oil for biodiesel production by glycerolysis: Investigation and optimization of process parameters. Green Process. Synth. 2019, 8, 15-23. [CrossRef]

46. Kombe, G.G. Re-esterification of high free fatty acid oils for biodiesel production. Biofuels 2015, 6, 31-36. [CrossRef]

47. Supardan, M.D.; Adisalamun Lubis, Y.M.; Annisa, Y.; Satriana Mustapha, W.A.W. Effect of co-solvent addition on glycerolysis of waste cooking oil. Pertanika J. Sci. Technol. 2017, 25, 1203-1210.

48. Mazubert, A.; Crockatt, M.; Poux, M.; Aubin, J.; Roelands, M. Reactor Comparison for the Esterification of Fatty Acids from Waste Cooking Oil. Chem. Eng. Technol. 2015, 38, 2161-2169. [CrossRef]

49. Farid, M.A.A.; Hassan, M.A.; Taufiq-Yap, Y.H.; Ibrahim, M.L.; Othman, M.R.; Ali AA, M.; Shirai, Y. Production of methyl esters from waste cooking oil using a heterogeneous biomass-based catalyst. Renew. Energy 2017, 114, 638-643. [CrossRef]

50. Borovinskaya, E.S.; Sabaditsch, D.; Reschetilowski, W. Base-Catalyzed Ethanolysis of Waste Cooking Oil in a Micro/Millireactor System: Flow and Reaction Analysis. Chem. Eng. Technol. 2019, 42, 495-505. [CrossRef] 
51. Steven, J.R. Synthetics, mineral oils, and bio-based lubricants: Chemistry and technology. In Chemical Industries; Rudnick, R.L., Ed.; CRC Press: Boca Raton, FL, USA, 2006.

52. Yunus, R.; Fakhru'1-Razi, A.; Ooi, T.L.; Biak DR, A.; Iyuke, S.E. Kinetics of transesterification of palm-based methyl esters with trimethylolpropane. J. Am. Oil Chem. Soc. 2004, 8, 497-503. [CrossRef]

53. Sun, G.; Li, Y.; Cai, Z.; Teng, Y.; Wang, Y.; Reaney, M.J.T. $\mathrm{K}_{2} \mathrm{CO}_{3}$-loaded hydrotalcite: A promising heterogeneous solid base catalyst for biolubricant base oil production from waste cooking oils. Appl. Catal. B Environ. 2017, 209, 118-127. [CrossRef]

54. Costarrosa, L.; Leiva-Candia, D.E.; Cubero-Atienza, A.J.; Ruiz, J.J.; Dorado, M.P. Optimization of the Transesterification of Waste Cooking Oil with Mg-Al Hydrotalcite Using Response Surface Methodology. Energies 2018, 11, 302. [CrossRef]

55. Mannu, A.; Ferro, M.; Colombo Dugoni, G.; Garroni, S.; Taras, A.; Mele, A. Response Surface Analysis of density and flash point in recycled Waste Cooking Oils. Chem. Data Collect. 2020, 25, 100329. [CrossRef]

56. Gupta, M.K. Practical Guide to Vegetable Oil Processing, 2nd ed.; Academic Press and AOCS Press: New York, NY, USA, 2017; ISBN 9781630670504.

57. Vlahopoulou, G.; Petretto, G.L.; Garroni, S.; Piga, C.; Mannu, A. Variation of density and flash point in acid degummed waste cooking oil. J. Food Process. Preserv. 2018, 42, e13533. [CrossRef]

58. Pellati, F.; Benvenuti, S.; Yoshizaki, F.; Bertelli, D.; Rossi, M.C. Head Space Solid Phase Micro Extraction Gas Chromatography coupled with Mass. J. Chromatogr. A 2005, 1087, 265-273. [CrossRef]

59. Ladhe, A.R.; Kumar, N.S.K. Application of Membrane Technology in Vegetable Oil Processing. Membr. Technol. 2010. [CrossRef]

60. Koris, A.; Vatai, G. Dry degumming of vegetable oils by membrane filtration. Desalination 2002, 148, 149-153. [CrossRef]

61. Ochoa, N.; Pagliero, C.; Marchese, J.; Mattea, M. Ultrafiltration of vegetable oils: Degumming by polymeric membranes. Sep. Purif. Technol. 2011, 22-23, 417-422. [CrossRef]

62. Pagliero, C.; Ochoa, N.; Marchese, J.; Mattea, M. Vegetable oil degumming with polyimide and polyvinylidene fluoride ultrafiltration membranes. J. Chem. Technol. Biotechnol. 2004, 79, 148-152. [CrossRef]

63. Desai, N.C.; Mehta, M.H.; Dave, A.M.; Mehta, J.N. Degumming of vegetable oil by membrane technology. Indian J. Chem. Technol. 2002, 9, 529-534.

64. De Moura, J.M.; Gonçalves, L.A.; Petrus, J.C.; Viotto, L.A. Degumming of vegetable oil by microporous membrane. J. Food Eng. 2005, 70, 473-478. [CrossRef]

65. Tur, E.; Onal-Ulusoy, B.; Akdogan, E.; Mutlu, M. Surface Modification of Polyethersulfone Membrane to Improve Its Hydrophobic Characteristics for Waste Frying Oil Filtration: Radio Frequency Plasma Treatment. J. Appl. Plymer Sci. 2011, 123, 3402-3411. [CrossRef]

66. Casallas, I.D.; Carvajal, E.; Mahech, E.; Castrillón, C.; Gómez, H.; López, C.; Malagón-Romero, D. Pretreatment of Waste Cooking Oils for Biodiesel Production. Chem. Eng. Trans. 2018, 65, 385-390. [CrossRef]

67. Weisshaar, R. Quality control of used deep-frying oils. Eur. J. Lipid Sci. Technol. 2014, 116, 716-722. [CrossRef]

68. Muraldihara, H.S.; Jirjis, B.F.; Seymour, G.F. Process for Removing Vegetable Oil Waxes by Fast Cooling Vegetable Oil and Using a Porous Non-Metallic Inorganic Filter. Available online: https://patents.google. com/patent/US5482633A/en (accessed on 19 March 2020).

69. Bertram, B.; Abrams, C.; Kauffman, J. Adsorbents Filtration System for Treating Used Cooking Oil or Fat in Frying Operations. Available online: https://patents.google.com/patent/US6368648B1/en (accessed on 19 March 2020).

70. Bivens, T.; Calrk, J.G. Filtration and Filtration Method for Cooking Oil Used in Frying Process. Available online: https://patents.google.com/patent/US20070289927A1/en (accessed on 19 March 2020).

71. Bivens, T.; Calrk, J.G. Method for Filtering Cooking Oil Used in Frying Process. Available online: https: //patents.google.com/patent/US8066889B2/en (accessed on 19 March 2020).

72. For EU See Waste Oil Directive 75/439/EEC. Available online: https://ec.europa.eu/environment/archives/ waste/oil/questionnaire.htm (accessed on 19 March 2020).

73. Available online: https://fryoilsaver.com/fry-oil-management/ (accessed on 4 March 2020).

74. Vlasova, E.A.; Yakimov, S.A.; Naidenko, E.V.; Kudrik, E.V.; Makarov, S.V. Application of metal-organic frameworks for purification of vegetable oils. Food Chem. 2016, 190, 103-109. [CrossRef] 
75. Mannu, A.; Vlahopoulou, G.; Sireus, V.; Petretto, G.L.; Mulas, G.; Garroni, S. Bentonite as a Refining Agent in Waste Cooking Oils Recycling: Flash Point, Density and Color Evaluation. Nat. Prod. Commun. 2018, 13, 613-616. [CrossRef]

76. Mannu, A.; Vlahopoulou, G.; Urgeghe, P.; Ferro, M.; Del Caro, A.; Taras, A.; Garroni, S.; Rourke, J.P.; Cabizza, R.; Petretto, G.L. Variation of the Chemical Composition of Waste Cooking Oils upon Bentonite Filtration. Resources 2019, 8, 108. [CrossRef]

77. Available online: https://www.lushunoilpurifier.com/product/productconnect?id=166\&gclid=Cj0KCQiA04Xx BRD5ARIsAGFygj_56-c-8FQiNadDYxYOHfUj4SXlaS0NAN5hLibRoBGB7bRxoHSOmi8aApDmEALw_wcB (accessed on 20 February 2020).

78. Available online: https://www.alibaba.com/product-detail/Stainless-Steel-Cooking-Oil-Filter-Machine_ 62090539203.html?spm=a2700.drainage_lp_1.0.0.43391199tvsgjr\&s=p (accessed on 20 February 2020).

79. Available online: https://ec.europa.eu/eurostat/statistics-explained/index.php?title=Electricity_price_ statistics/es\#Precios_de_la_electricidad_para_los_consumidores_dom.C3.A9sticos (accessed on 20 February 2020).

80. Luzuriaga, S. Bio-lubricants: Global opportunities and challenges. Tribol. Lubr. Technol. 2017, 73, 16-19.

81. Kofi, S.; Kotoka, T.F. The potential of castor, palm kernel, and coconut oils as biolubricant base oilvia chemical modification and formulation. Therm. Sci. Eng. Progress 2020, 16, 1004802. [CrossRef]

82. Manawwer, A.; Deewan, A.; Eram, S.; Fahmina, Z.; Sharif, A. Vegetable oil based eco-friendly coating materials: A review article. Arab. J. Chem. 2014, 7, 469-479. [CrossRef]

(C) 2020 by the authors. Licensee MDPI, Basel, Switzerland. This article is an open access article distributed under the terms and conditions of the Creative Commons Attribution (CC BY) license (http://creativecommons.org/licenses/by/4.0/). 